\title{
PENDAMPINGAN PENINGKATAN KOMPETENSI ILMIAH DAN KEWIRAUSAHAAN GURU SD MUHAMMADIYAH KARANGTURI MELALUI PENULISAN BUKU
}

\author{
Filosa Gita Sukmono, dan Fajar Junaedi \\ Program Studi Ilmu Komunikasi, Universitas Muhammadiyah Yogyakarta \\ E-mail: filosa@umy.ac.id
}

\begin{abstract}
ABSTRAK. SD Muhammadiyah Karangturi merupakan SD Muhammadiyah yang sedang berkembang. Perkembangan ini ditandai dengan jumlah pelajar yang setiap tahun mencapai dua kelas pararel dan pembangunan fisik gedung sekolah yang sedang dibangun setinggi tiga lantai. Lokasi SD Muhammadiyah Karangturi yang strategis yaitu di samping kantor Kecamatan Banguntapan, Bantul merupakan potensi strategis yang perlu dikelola dengan baik. Sayangnya potensi ini berhadapan dengan persoalan yang terjadi dalam aspek sumber daya manusia. Persoalan yang muncul di SD Muhammadiyah Karangturi adalah rendahnya kemampuan guru dalam penulisan ilmiah. Ini diindikasikan dengan belum adanya publikasi ilmiah yang ditulis oleh guru SD Muhammadiyah Karangturi. Untuk mengatasi persoalan ini, maka metode yang digunakan dalam Program Kemitraan Masyarakat berjudul Pendampingan Peningkatan Kompetensi Ilmiah dan Kewirausahaan Guru SD Muhammadiyah Karangturi melalui Penulisan Buku. Kegiatan dilaksanakan dengan melalui rangkaian pelatihan penulisan ilmiah yang dilanjutkan dengan penulisan buku yang berisi kumpulan karya tulis ilmiah guru SD Muhammadiyah Karangturi. Kesimpulan dari kegiatan ini dengan kemampuan penulisan, guru akan meningkat kompetensi akademiknya sekaligus memiliki kemampuan wirausaha ekonomi kreatif di bidang penulisan. Buku yang dicetak adalah sebanyak 200 eksemplar yang akan dijual secara komersial dengan keseluruhan keuntungan digunakan untuk mitra sebagai modal untuk penerbitan buku selanjutnya. Hal ini merupakan proses penting dari keberlanjutan program ini, dimana mitra membentuk Komunitas Guru Penulis sebagai bagian keberlanjutan program.
\end{abstract}

Kata Kunci: Pendidikan; Guru; Penulisan Ilmiah; Kewirausahaan; Buku

ABSTRACT. Muhammadiyah Karangturi Elementary School is a developing Muhammadiyah primary educational institution. The progress is marked with the higher yearly number of students, which amount to two parallel classes, and the construction of the threestory building. The strategic location of the school placed beside the sub-district office of Banguntapan, Bantul, is a potential advantage that calls for a well-management. However, the potency had to deal with human resource's issues, namely the lower skills of the teacher in academic writing. It is indicated by the fact that the teachers had never published a scientific publication yet. To tackle the problem, the Society Partnership Program entitled Supervision and Enhancement of Scientific Competence and Entrepreneurship for Muhammadiyah Karangturi Elementary School Teachers was proposed by implementing book writing training. The activity was conducted through a set of workshops in academic writing that was followed by a book writing process, which eventually will be collected in the form of an anthology comprising of the teachers'works. This activity demonstrated that by having writing competence, academic competence and entrepreneurial skill as to the creative economy of the teachers in the field of writing increased significantly. Two hundred books have been printed and will be distributed commercially, and the profit will be used by the school to process further book-making. The last process is critical for the sustainability of the program, and the Writer Teacher Community was formed to realize it by the school.

Key words: Education; Teachers; Scientific Writing; Enterprenership; Books.

\section{PENDAHULUAN}

Sekolah Dasar (SD) Muhammadiyah Karangturi, Banguntapan, Bantul sampai tahun 2010 berada dalam kondisi yang kurang baik. Manajemen dan tata kelola sekolah yang tidak baik menyebabkan SD Muhammadiyah Karangturi tidak banyak diminati masyarakat bahkan terancam tutup. Kondisi mulai berubah pasca tahun 2010, ketika manajemen dan tata kelola sekolah mulai diperbaiki. Di tahun ajaran 2018/2019, jumlah murid baru yang diterima di SD Muhammadiyah Karangturi adalah sebanyak dua kelas, yang masing-masing kelas terdiri dari 30 murid. Berbarengan dengan perbaikan tata kelola dan manajemen sekolah, SD Muhammadiyah Karangturi bergeliat membangun gedung sekolah yang semakin representatif.

SD Muhammadiyah Karangturi memiliki potensi dikembangkan menjadi SD unggulan di kawasan timur Yogyakarta. Secara geografis, lokasi SD Muhammadiyah Karangturi sangat menguntungkan, yaitu berada di samping kantor kecamatan Banguntapan, hanya berjarak
500 m dari Jalan Ring Road Timur dan hanya berjarak 1 km dari Kotagede, Kota Yogyakarta. Dengan lokasi ini, SD Muhammadiyah Karangturi berpotensi diminati dari dua wilayah yaitu Kecamatan Banguntapan Bantul dan Kecamatan Kotagede Kota Yogyakarta.

Peluang pengembangan SD Muhammadiyah Karangturi sebagai sekolah unggulan sangat besar, mengingat di kawasan Banguntapan kini tumbuh pesat kompleks perumahan. Jumlah pendatang yang terus datang di kawasan kompleks perumahan baru merupakan potensi pasar bagi pengembangan sekolah.

Persoalan yang ada di SD Muhammadiyah Karangturi adalah kompetensi guru dalam penulisan ilmiah. Kemampuan guru dalam penulisan ilmiah belum cukup baik. Padahal kemampuan penulisan ilmiah penting untuk peningkatan kemampuan mengajar, dan sekaligus juga Pengembangan Keprofesian Berkelanjutan (PKB) adalah pengembangan kompetensi guru yang dilaksanakan sesuai dengan kebutuhan, bertahap, dan berkelanjutan untuk meningkatkan profesionalitasnya. 
Kurang mampunya guru dalam penulisan ilmiah ditandai dengan belum adanya publikasi ilmiah yang dihasilkan oleh guru. PKB bagi guru mencakup tiga kegiatan yaitu: (1) pengembangan diri; (2) publikasi ilmiah; dan (3) karya inovatif. Tujuan umum PKB adalah untuk meningkatkan kualitas layanan pendidikan di sekolah dalam rangka meningkatkan mutu pendidikan. PKB semakin relevan dengan diterapkannya Peraturan Menteri Pendayagunaan Aparatur Negara dan Reformasi Birokrasi (Menpan \& RB) Nomor 16 Tahun 2009 tentang Jabatan Fungsional Guru dan Angka Kreditnya. Dalam hal ini setiap guru dituntut untuk menyusun rencana pengembangan diri melalui program PKB (Masduki dan Kholid, 2017 :121). Manfaat lanjutan adalah dengan penulisan ilmiah, guru bisa mengembangkan kemampuan kewirausahaan melalui penjualan buku karya mereka. Dengan demikian, permasalahan prioritas adalah bagaimana meningkatkan kompetensi guru dalam penulisan ilmiah serta sekaligus mengembangkan kewirausahaan sebagai penulis buku?

Justifikasi program yang disusun bersama mitra dalam menentukan persoalan prioritas ini didasarkan pada pertimbangan sebagai perikut. Pertama, persoalan kemampuan penulisan ilmiah merupakan persoalan mendasar dalam kompetensi guru di SD Muhammadiyah Karangturi. Kedua, mitra belum mengetahui prosedur penerbitan karya ilmiah menjadi buku. Ketiga, tim dari Universitas Muhammadiyah Yogyakarta memiliki kemampuan dan pengalaman dalam penulisan buku ilmiah dan distribusi serta mekanisme penjualan buku yang bisa dibagikan kepada mitra.

Solusi yang ditawarkan untuk menyelesaikan permasalahan mitra adalah dengan literasi media kepada guru. Elemen-elemen literasi media menurut Art Silverblatt (1995), diantaranya: (1) kesadaran akan pengaruh media terhadap individu dan sosial; (2) pemahaman akan proses komunikasi massa; (3) pengembangan strategi untuk menganalisis dan mendiskusikan pesan media; (4) kesadaran bahwa isi media adalah teks yang menggambarkan kebudayaan dan diri kita sendiri pada saat ini; dan (5) mengembangkan kesenangan, pemahaman, dan penghargaan terhadap isi media (Silverbalt dalam Gumilar, Adiprasetio dan Maharani, 2017:38). James Potter (2008: 19) menyebutkan bahwa literasi media adalah seperangkat perspektif yang secara aktif mendorong kita untuk menafsirkan pesan media yang kita terima (a set of perspectives that we actively use to expose ourselves to the media to interpret the meaning of the messages we encounter) Sedang pengertian yang disepakati dalam The National Leadership Conference on Media Literacy adalah kemampuan untuk mengakses, menganalisis, mengevaluasi dan mengkomunikasikan pesan dalam beragam bentuk (the ability to access, analyze, evaluate dan communicate messages in a variatey of form) (Eadie, 2009: 560).

Tujuan dari pengabdian masyarakat ini adalah untuk meningkatkan kompetensi guru dalam karya tulis ilmiah, meningkatkan jumlah publikasi buku dari guru SD Muhammadiyah Karangturi Bantul. Kontribusi yang diharapkan dari program pengabdian adalah terbitnya buku pertama karya guru SD Muhammadiyah Karangturi Bantul, yang menjadi awal dari publikasi buku selanjutnya sehingga ada keberlanjutan program pengabdian masyarakat.

\section{METODE}

Metode pengabdian masyarakat ini adalah sebagai berikut. Pertama, memberikan pelatihan penulisan artikel ilmiah populer kepada guru SD Muhammadiyah Karangturi. Yang dimaksudkan dengan artikel ilmiah populer di sini adalah artikel dalam format artikel populer yang biasa dipublikasikan di media massa. Kegiatan pelatihan dilangsungkan selama satu hari di SD Muhammadiyah Karangturi dengan peserta sebanyak 50 orang. Agar pelatihan berlangsung dengan efektif, peserta dibagi ke dalam dua ruang kelas yang masing-masing terdiri dari 25 orang peserta. Di setiap ruang pelatihan, peserta didampingi oleh pemateri dariUniversitas Muhammadiyah Yogyakarta.

Kedua, setelah mengikuti pelatihan, peserta langsung melakukan praktek penulisan artikel. Tema utama yang menjadi payung dari keseluruhan artikel yang ditulis oleh peserta adalah pendidikan karakter. Dalam sesi yang dilaksanakan sebagai kontinuitas dari pelatihan penulisan artikel ilmiah populer ini, pemateri dari Universitas Muhammadiyah Yogyakarta berubah peran menjadi fasilitator. Sebagai fasilitator, tugas yang utama adalah memberikan pendampingan kepada peserta yang sedang melakukan praktek penulisan ilmiah populer. Setiap peserta ditargetkan mampu menulis artikel sepanjang 3 sampai 4 halaman spasi ganda.

Ketiga, difusi ipteks melalui penerbitan keseluruhan karya peserta dalam sebuah buku. Meskipun buku yang diterbitkan adalah buku antologi, isi buku terjalin secara sambung menyambung karena sejak awal pemateri dan fasilitator selalu mengarahkan peserta untuk menulis tema yang berkaitan dengan pendidikan karakter berdasarkan pengalaman guru di sekolah. Difusi ipteks ini dilanjutkan dengan pendampingan kepada guru SD Muhammadiyah Karangturi dalam distribusi dan penjualan buku. Keseluruhan hasil penjualan buku diserahkan kepada SD Muhammadiyah Karangturi, untuk dibagi sebagai royalti guru-guru yang menulis, dan modal untuk penerbitan buku lain di masa mendatang. Mekanisme ini diharapkan menghasilkan program yang berkelanjutan di masa mendatang.

\section{HASIL DAN PEMBAHASAN}

Sejak program pengabdian masyarakat ini dirancang, mitra sudah dilibatkan dalam penyusunan proposal. Pelibatan mitra sejak dini ditujukan agar persoalan yang dihadapi mitra dapat dirumuskan dengan baik, dan selanjutnya disusun rancangan penyelesaian mengenai 
persoalan yang dihadapi mitra. SD Muhammadiyah Karangturi menghendaki agar guru yang mengikuti pelatihan bukan hanya dari SD Muhammadiyah Karangturi, namun juga guru-guru di sekolah lain di sekitar SD Muhammadiyah Karangturi sejumlah 50 orang. Akhirnya diputuskan bahwa 60 persen peserta atau 30 orang adalah guru SD Muhammadiyah Karangturi yang diwajibkan untuk mengikuti program pelatihan, dan 40 persen atau 20 orang dari sekolah lain.

Publikasi kegiatan dilakukan dengan poster digital yang disebarkan melalui media sosial. Implikasi dari publikasi kegiatan sangat positif karena hanya dalam waktu dua hari sejak publikasi diunggah di media sosial, kuota peserta langsung terpenuhi.

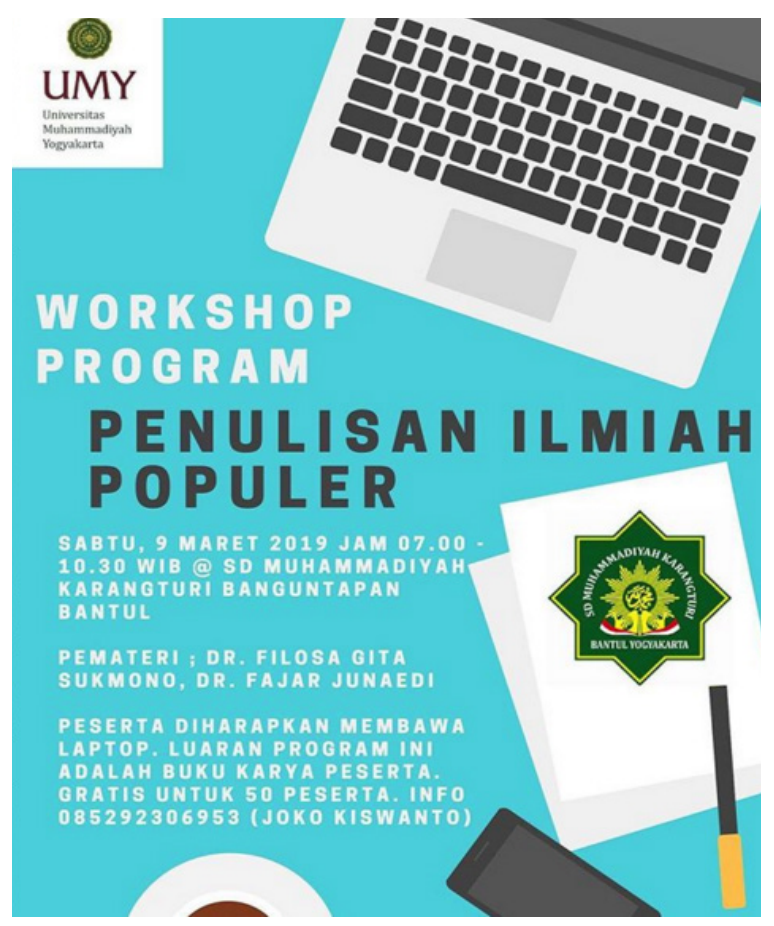

Gambar 1. Poster kegiatan pelatihan penulisan ilmiah populer.

Pada hari Minggu, tanggal 10 Maret 2019, kegiatan pelatihan penulisan ilmiah populer dilangsungkan di SD Muhammadiyah Karangturi. Sesuai dengan rancangan kegiatan, peserta dibagi dalam dua orang yang masingmasing terdiri dari 25 peserta. Ruangan yang digunakan adalah ruang kelas yang ada di SD Muhammadiyah Karangturi.

Setelahsesipelatihan,pesertadiajakuntukmelakukan praktek penulisan. Dalam praktek penulisan ini, pemateri berubah peran menjadi fasilitator. Sebagai fasilitator, tugas yang diemban adalah memberikan pendampingan kepada setiap peserta dalam mengembangkan artikel ilmiah popu-ler yang mereka tulis. Target yang diberikan kepada peserta adalah mampu menulis sepanjang dua sampai empat halaman spasi ganda.

Struktur artikel yang harus ditulis oleh peserta adalah judul, tubuh artikel dan biodata. Tubuh artikel menjadi bagian utama yang harus ditulis oleh peserta. Jika peserta mengutip dari buku atau jurnal, maka pengutipan ditulis dalam tubuh artikel. Hal ini dikarenakan buku yang dirancang adalah buku ilmiah populer. Fasilitator selalu memberikan penekanan kepada peserta untuk tidak melakukan plagiarisme dengan selalu menyebutkan sumber kutipan pada artikel yang mereka tulis.

Sejak awal peserta telah diminta untuk membawa laptop, namun bagi peserta yang tidak memiliki laptop tetap diperkenankan mengikuti kegiatan pelatihan. Peserta yang tidak memiliki laptop diminta untuk menulis artikel dalam format tulisan tangan. Tugas fasilitator dalam hal ini adalah memindahkan artikel yang masih ditulis tangan ke dalam format artikel yang diketik rapi di laptop melalui aplikasi Microsoft Word.

Peserta diberi waktu selama tiga jam untuk menulis artikel ilmiah populer, dengan pertimbangan, penulisan satu halaman artikel ilmiah populer membutuhkan waktu sekitar satu jam. Setelah tiga jam menulis, peserta diminta untuk mengirimkan file melalui surat elektronik (e-mail) masing-masing fasilitator.

Meskipun telah diberi waktu untuk menulis, tidak semua peserta mampu menyelesaikan artikel ilmiah populer yang merak tulis. Bagi peserta yang belum selesai, fasilitator memberikan kesempatan untuk menyelesaikan di rumah masing-masing dengan batas waktu pengumpulan tiga hari. Sebelum acara pelatihan dan pendampingan praktek penulisan ditutup, fasilitator mengajak peserta untuk mendiskusikan judul buku. Fasilitator memberikan petunjuk kepada peserta sebagai acuan diskusi tentang pertimbangan-pertimbangan penentuan judul. Pertama, judul harus mampu memayungi semua judul artikel. Kedua, judul harus mampu menarik minat pembaca untuk membaca buku. Terakhir, judul harus mudah dieksekusi menjadi sampul buku. Dengan pertimbangan ketiga hal ini, disepakatilah judul buku "Menyemai Pendidikan Karakter, Merawat Sekolah Inklusif”.

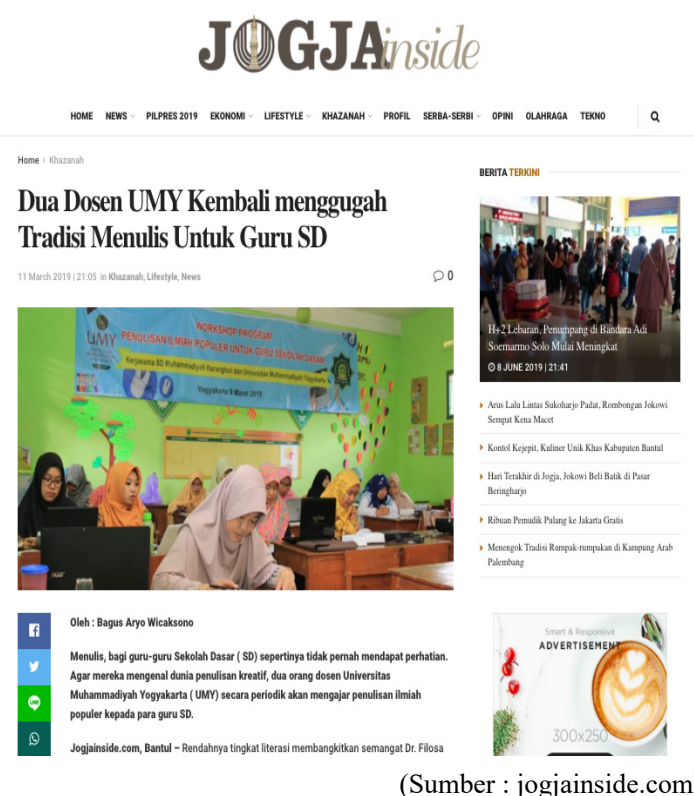

(Sumber : jogjainside.com)

Gambar 2. Pemberitaan kegiatan pengabdian di media massa 
Setelah semua artikel terkumpul, tim pengabdian masyarakat dari Universitas Muhammadiyah Yogyakarta berganti peran dari fasilitator menjadi editor buku. Setiap artikel yang ditulis oleh guru peserta disunting isi dan tata bahasanya, selanjutnya dikompilasi ke dalam satu file. Setelah terkumpul dalam satu file, naskah draft buku diserahkan kepada penerbit Buku Litera untuk ditata letak (lay out). Dalam waktu dua hari dummy buku telah selesai dibuat oleh penerbit. Dummy buku kemudian diserahkan kepada perwakilan guru SD Muhammadiyah Karangturi untuk dicek, disunting ulang dan diselaraskan aksaranya (proof reading). Tim pengabdian masyarakat Universitas Muhammadiyah Yogyakarta melakukan proses pendampingan dalam proses ini.

Pada saat dummy buku sedang dicek, disunting ulang dan diselaraskan aksaranya, tim pengabdian masyarakat mencarikan kata pengantar untuk buku. Dalam waktu satu minggu didapatkan kata pengantar dari Menteri Pendidikan dan Kebudayaaan, Prof. Dr. Muhadjir Effendy, dan Rektor Universitas Muhammadiyah Yogyakarta, Dr. Gunawan Budiyanto.

Setelah dummy buku selesai menjalani proses proof reading, dummy buku kembali diserahkan kepada penerbit. Revisi yang ada di dummy buku menjadi acuan penyelerasan terakhir. Pada proses yang bersamaan, kata pengantar dimasukan ke dalam naskah buku. Tahap penerbitan buku dilakukan dengan pembuatan master naskah buku, penggandaan master, pencetatan sampul, penjilidan dan pengemasan buku dalam plastik tipis. Proses ini membutuhkan waktu empat hari.

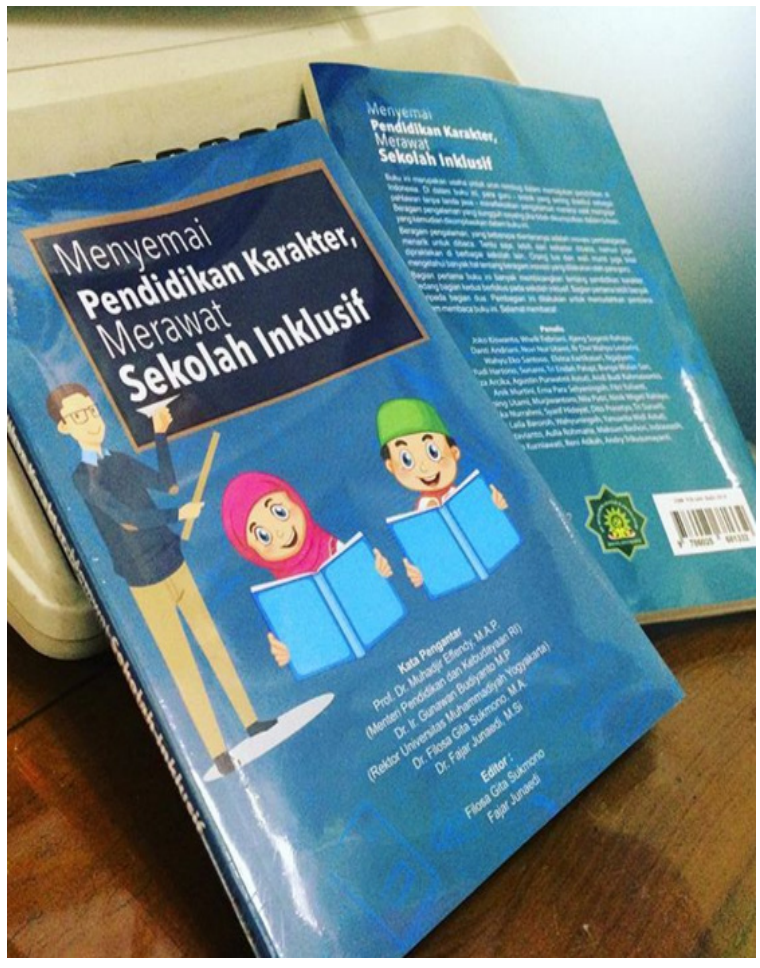

(Sumber : Dokumentasi Pribadi)

Gambar 3. Buku Menyemai Pendidikan Karakter, Merawat Sekolah Inklusif karya guru peserta program pelatihan
Buku yang telah selesai dicetak diserahkan kepada SD Muhammadiyah Karangturi sejumlah 200 eksemplar. Keseluruhan hasil penjualan buku menjadi hak SD Muhammadiyah Karangturi dan guru-guru yang menjadi penulis. Dengan demikian, SD Muhammadiyah Karangturi bisa memiliki modal untuk penerbitan buku lain di tahun-tahun mendatang, sehingga ada keberlanjutan program ini. Di sisi yang lain guru mendapatkan royalti dari penjualan buku sebagai bentuk apresiasi dan penumbuh kembangan kewirausahaan di sektor ekonomi kreatif sub sektor penerbitan buku. Guru juga diberikan kesempatan menjadi reseller buku dan juga mendapatkan royalti dari penjualan buku.

Program pengabdian ini telah membawa perubahan pada institusi mitra dan guru yang mengikuti program. Perubahan yang terjadi bisa digambarkan sebagai berikut:

Tabel 1. Perubahan Kondisi Sebelum dan Sesudah Program Pengabdian

\begin{tabular}{|c|c|c|c|}
\hline \multirow{2}{*}{ No. } & \multirow{2}{*}{ Kondisi } & \multicolumn{2}{|c|}{ Perubahan } \\
\hline & & Sebelum & Sesudah \\
\hline 1. & $\begin{array}{l}\text { Penulisan artikel } \\
\text { ilmiah populer yang } \\
\text { terpublikasikan. }\end{array}$ & $\begin{array}{l}\text { Guru belum } \\
\text { pernah mem- } \\
\text { publikasikan } \\
\text { artikel. }\end{array}$ & $\begin{array}{l}\text { Guru } \\
\text { mempublikasikan } \\
\text { artikel ilmiah } \\
\text { populer dalam } \\
\text { bentuk buku. }\end{array}$ \\
\hline 2. & $\begin{array}{l}\text { Penerbitan buku } \\
\text { ber-ISBN oleh guru. }\end{array}$ & $\begin{array}{l}\text { Belum pernah } \\
\text { dilakukan. }\end{array}$ & $\begin{array}{l}\text { Ada penerbitan } \\
\text { buku ber-ISBN. }\end{array}$ \\
\hline 3. & $\begin{array}{l}\text { Proses penyelarasan } \\
\text { aksara dan } \\
\text { penyuntingan buku. }\end{array}$ & $\begin{array}{l}\text { Belum pernah } \\
\text { dialami. }\end{array}$ & $\begin{array}{l}\text { Pernah } \\
\text { mengalami. }\end{array}$ \\
\hline 4. & $\begin{array}{l}\text { Penerbitan } \\
\text { buku oleh SD } \\
\text { Muhammadiyah } \\
\text { Karangturi. }\end{array}$ & $\begin{array}{l}\text { Belum pernah } \\
\text { dilakukan. }\end{array}$ & $\begin{array}{l}\text { Penerbitan } \\
\text { buku oleh SD } \\
\text { Muhammadiyah } \\
\text { Karangturi bekerja } \\
\text { sama dengan } \\
\text { Universitas } \\
\text { Muhammadiyah } \\
\text { Yogyakarta dan } \\
\text { Penerbit Buku } \\
\text { Litera. }\end{array}$ \\
\hline
\end{tabular}

Setelah buku terbit, salah seorang peserta, Joko Kiswanto S.Pd dari SD Muhammadiyah Karangturi, berhasil meraih peringkat ketiga dalam pemilihan guru berprestasi se-Kabupaten Bantul. Buku Menyemai Pendidikan Karakter, Merawat Sekolah Inklusif menjadi salah satu portofolio yang digunakan dalam pemilihan ini. Hambatan yang muncul dalam program pengabdian ini adalah adanya guru yang tidak mengumpulkan artikelnya sampai batas waktu yang ditentukan. Hal ini menyebabkan tidak semua guru peserta pelatihan terpublikasikan karya artikelnya.

\section{SIMPULAN}

Program pengabdian masyarakat ini telah berjalan dengan sangat baik. Ketercapaian target yaitu terbitnya buku karya guru, sesuai dengan durasi waktu yang direncanakan merupakan indikator kesuksesan program ini. Indikator 
selanjutnya adalah terjadinya perubahan pada mitra sebelum dan setelah program pengabdian dilaksanakan. Kerja sama yang baik antara tim dari Universitas Muhammadiyah Yogyakarta dan SD Muhammadiyah Karangturi menjadi kunci kelancaran program pengabdian ini.

Program ini terus terjaga keberlanjutannya karena SD Muhammadiyah Karangturi telah memiliki modal dari penjualan buku sebagai biaya penerbitan buku-buku lain di masa mendatang. Guru-guru SD Muhammadiyah Karangturijugatelahmemilikikompetensidanpengalaman dalam penulisan buku. Untuk program pengabdian sejenis di masa mendatang, perlu kiranya memberikan perhatian lebih kepada guru yang tidak mengumpulkan artikelnya. Perhatian mulai diberikan saat pelatihan, terutama dengan melihat performa guru saat pelatihan.

\section{UCAPAN TERIMAKASIH}

Terima kasih kami haturkan kepada Dr. Gunawan Budiyanto, rektor Universitas Muhammadiyah Yogyakarta, dan Dr. Gatot Supangkat, kepala LP3M Universitas Muhammadiyah Yogyakarta untuk dukungannya dalam program pengabdian masyarakat ini. Terima kasih kepada SD Muhammadiyah Karangturi yang telah menjadi mitra yang sangat kooperatif dalam pelaksanaan program. Terima kasih kepada Menteri Pendidikan dan Kebudayaan Republik Indonesia, Prof. Dr. Muhadjir Effendy yang telah bersedia memberikan kata pengantar untuk buku Menyemai Pendidikan Karakter, Merawat Sekolah Inklusif.

\section{DAFTAR PUSTAKA}

Gumilar, G; Adiprasetio, J, dan Maharani, N. (2017). Literasi Media: Cerdas Menggunakan Media Sosial dalam Menanggulangi Berita Palsu (Hoax) oleh Siswa SMA, dalam Jurnal Pengabdian Kepada Masyarakat Vol. 1, No. 1, Februari 2017: 35 - 40

Eadie, F. William. [Ed].( 2009). 21st Century Communication A Reference

Handbook, Volume 2. Thousand Oaks, California: SAGE Publications, Inc

Masduki, dan Kholid, MN (2017) Pengembangan Kemampuan Penelitian dan Penulisan Karya Ilmiah Bagi Guru Matematika SMA/SMK Muhammadiyah di Klaten dan Sukoharjo dalam Jurnal WARTA LPM, Vol. 20, No. 2, September 2017: 115-122

Potter, J dalam William F. E (ed.) 2009. 21st Century Communication A Reference Handbook, Volume 2. Thousand Oaks, California, SAGE Publications, Inc.

Potter, J. 2008. Media Literacy (4th ed.). Thousand Oaks: Sage Publications Inc. 